\title{
Assessment of the auxiliary gas flow and torch position influence on measurement of Lu-Hf isotopic composition of zircon by a direct identification of ${ }^{177} \mathrm{HfO} /{ }^{177} \mathrm{Hf}$ formation rates with MC-ICP-MS
}

\author{
$\mathrm{CHAO} \mathrm{HUANG}^{12}$, YUE-HENG YANG ${ }^{12}$, LIE-WEN \\ $\mathrm{XIE}^{12}$, SHI-TOU WU ${ }^{12}$, HAO WANG ${ }^{12}$, JIN-HUI \\ YANG $^{12}$
}

${ }^{1}$ State Key Laboratory of Lithospheric Evolution, Institute of Geology and Geophysics, Chinese Academy of Sciences, Beijing, 100029, China

${ }^{2}$ Innovation Academy for Earth Science, Chinese Academy of Sciences, Beijing, 100029 China

Lu-Hf systematics has widespread applications in geochemistry. In the past few decades, the use of multiplecollector inductively coupled plasma mass spectrometry (MC-ICP-MS) has improved the precision and accuracy of Lu-Hf analysis. Unfortunately, a major challenge of isobaric and polyatomic spectral interferences still exists in accurate measurement. Oxide ions of elements are one of the most problematic interferences which are abundantly in samples. In this contribution we present a new methodology for Lu-Hf analysis by a direct identification of ${ }^{177} \mathrm{HfO} /{ }^{177} \mathrm{Hf}$ formation rates with MC-ICP-MS. Specifically, the effects of the auxiliary gas flow and torch position on measurement of Lu$\mathrm{Hf}$ isotopic composition of zircon are explored by identifying ${ }^{177} \mathrm{HfO} /{ }^{177} \mathrm{Hf}$ formation rates directly.

For solution analysis of Lu-Hf, the achieved relationship between ${ }^{177} \mathrm{HfO} /{ }^{177} \mathrm{Hf}$ ratios and the auxiliary gas flow is exponential. Moreover, the range from $0.5 \mathrm{l} / \mathrm{min}$ to $0.8 \mathrm{l} / \mathrm{min}$ used for the auxiliary gas flow is appropriate. If the flow is higher than $0.8 \mathrm{l} / \mathrm{min}$ or lower than $0.5 \mathrm{l} / \mathrm{min}$, the obtained ratio will be higher or lower than the recommended value of ${ }^{176} \mathrm{Hf} /{ }^{177} \mathrm{Hf}$. The ${ }^{177} \mathrm{HfO} /{ }^{177} \mathrm{Hf}$ ratios were $0.92 \%, 0.34 \%$, $0.29 \%, 0.27 \%$ and $0.26 \%$, corresponding to $-4 \mathrm{~mm},-2 \mathrm{~mm}$, $0 \mathrm{~mm}, 2 \mathrm{~mm}$ and $4 \mathrm{~mm}$ of the $\mathrm{z}$ position of the torch. If changing $\mathrm{z}$ position of the torch, although the ${ }^{176} \mathrm{Hf} /{ }^{177} \mathrm{Hf}$ isotope ratios showed some slight change, they are within uncertainty equivalent to the recommended value. For laser ablation analysis, when the auxiliary gas flow was tuned from $0.7 \mathrm{l} / \mathrm{min}$ to $1.1 \mathrm{l} / \mathrm{min}$, the ${ }^{177} \mathrm{HfO} /{ }^{177} \mathrm{Hf}$ hardly changed. And the obtained ${ }^{176} \mathrm{Hf} /{ }^{177} \mathrm{Hf}$ isotope ratio showed slight change, which are consistent with the recommended value.

(Correspondence: huangchao@mail.iggcas.ac.cn) 